\title{
¿Estimation of Wind Speed and Roughness Length Using Smartphones: Method and Quality Assessment
}

\author{
K. S. HINTZ AND H. VEDEL \\ Danish Meteorological Institute, Copenhagen, Denmark \\ E. KAAS \\ Niels Bohr Institute, University of Copenhagen, Copenhagen, Denmark \\ N. W. NIELSEN \\ Danish Meteorological Institute, Copenhagen, Denmark
}

(Manuscript received 11 March 2019, in final form 28 April 2020)

\begin{abstract}
Crowdsourced data are now seen as a potential source of high-resolution observations in the atmospheric sciences. In this paper we investigate a potential data source, wind observations obtained using anemometers connected to handheld smartphones. The aim of this paper is twofold: to assess the quality of raw and heightextrapolated wind measurements from the handheld anemometer against professional-grade surface synoptic observation (SYNOP) stations, and to use these data of opportunity to infer a more accurate estimation of terrain roughness lengths. Roughness lengths are essential in numerical weather prediction; however, they are often poorly determined. Roughness lengths are also necessary when correcting near-surface wind observations for height offsets. For the analysis we performed a series of field experiments measuring wind profiles using handheld anemometers at roughly $2 \mathrm{~m}$ above ground. These raw measurements were then extrapolated to 10 -m height using roughness lengths from three different sources. The extrapolation enabled us to compare the quality of roughness lengths estimated from smartphone measurements with those from traditional sources, as well as to assess the quality of these wind measurements against the professional-grade stations. We find that the handheld wind measurements are comparable in quality to wind measurements from SYNOP stations at 10-m height and that for some cases the handheld measurements can be more representative than SYNOP stations only about a kilometer away. To determine the roughness lengths, we examine a method that is based on the turbulent intensity derived from the high-frequency signal of the smartphone wind measurements. Under certain circumstances, the roughness lengths obtained with the approach presented here are superior to traditional sources.
\end{abstract}

\section{Introduction}

The spatial resolution of numerical weather prediction (NWP) models increases steadily, whereas the conventional meteorological observing network is not densifying at the same rate, if at all. This results in a lack of observations to validate, fine tune, and initialize NWP models. A potential new source of observation data is the so-called crowdsourced data from devices owned by

๑ Denotes content that is immediately available upon publication as open access.

Corresponding author: K. S. Hintz, kah@dmi.dk citizens. To cite Howe (2006), crowdsourced data can be defined broadly as "the act of taking a job traditionally performed by a designated agent (usually an employee) and outsourcing it to an undefined, generally large group of people in the form of an open call."' The term crowdsourcing is used in many applications and is in general broad (Arolas and Guevara 2012). In addition to the usage in NWP, crowdsourced data can provide extra information about the state of the atmosphere to operational meteorologists (Agüera-Pérez et al. 2014; Clark et al. 2018).

In recent years the number of low-cost personal devices connected to the internet and mobile network has increased substantially (Evans 2011), potentially 
providing new observations for use in the atmospheric sciences. These sensors can either run fully automated, such as barometric sensors in smartphones (Kim et al. 2015), or they need to be operated by humans, such as in the Meteorological Phenomena Identification Near the Ground (mPING) (NSSL 2016) project. Barometric pressure obtained via smartphones has been suggested by Mass and Madaus (2014) as a data source to improve forecasts of mesoscale phenomena. McNicholas and Mass (2018) and Hintz et al. (2019a) assimilated smartphone pressure observations and found them to increase forecast skill. The Weather Observations Website (WOW) project is examining how to collect data from personal weather stations (PWS) as additional data (Met Office 2017). The privately owned company Netatmo SAS (Netatmo SAS 2017) manufactures personal weather stations and collects data from all over the world. Netatmo has recently partnered with the Norwegian national meteorological service Yr (Netatmo SAS 2018). A comprehensive overview of current crowdsourcing activities in NWP is given by Hintz et al. (2019b), and Krennert et al. (2018) give a more general overview of recent crowdsourcing activities within Europe.

Obtaining handheld wind measurements (HWMs) has recently become possible with low-cost anemometers that can be attached to smartphones. In this study we investigate the use of such observations, made with a particular cup anemometer for smartphones manufactured by Vaavud ApS. Other manufacturers exist, such as WeatherFlow, Inc. The Vaavud anemometer measures both wind speed and wind direction, possible because of its asymmetric rotor design. It is a low-cost anemometer that is easily affordable for "the crowd." Apparent pitfalls exist, related both to the quality of the measurement devices themselves and related to the nonideal behavior of the user, who might stand next to an obstacle, not hold it horizontally, or even have fun blowing on the anemometer. Such problems are common to all types of crowdsourced data, but if these problems can be worked around, there will be access to an enormous amount of additional meteorological observations at a low cost.

The objective of this study is twofold. First, and most important, is to quantify the quality of HWMs coming directly from the handheld anemometer relative to traditional wind observations obtained following the requirements of WMO (2008, chapter 5). As more and more observations from smartphones can be received in real or near-real time, it is relevant to consider if such observations can be used to increase the information about specific weather phenomena for operational meteorologists. To do so, it is critical first to investigate how HWMs compares to traditional wind observations. It is also examined if extrapolating the HWMs with height to $10 \mathrm{~m}$ gives better results when compared with the WMO standards. This requires knowledge of the atmospheric stability and $z_{0}$, the roughness length of the surface. A second objective of our study is to investigate whether HWMs can be used to estimate local roughness lengths by utilizing the horizontal turbulent intensity, as suggested by Counihan (1975). The horizontal turbulent intensity can be estimated from the high-frequency smartphone wind measurements. Such an approach is tested by using the derived roughness length as a parameter in an extrapolation of the HWM with height to compare to a professional high-precision reference measurement at $10 \mathrm{~m}$. By using this approach, we focus on methods that can be easily implemented in practice, requiring no need for professional equipment that is too expensive for the crowd. In this way, it is the hope that the method presented in this study is scalable and easy to implement in practice, opening possibilities for new observation types for operational weather forecasting.

For this study, the majority of the measurements were performed by the authors. Some of the measurement campaigns were carried out not far from two surface synoptic observation (SYNOP) stations operated by the Danish Meteorological Institute (DMI) to allow comparison with the official DMI wind measurements. An additional reason for the focus on roughness length is that it is of vital importance also to NWP since roughness length is closely related to the estimation of near-surface winds and surface fluxes of sensible heat, moisture, and momentum (Arya 2001).

\section{Method}

The basis of this study is a set of measurement sessions made at three different locations (see section $2 b$ ). In each session two wind measuring devices, a handheld anemometer and a reference high-precision sonic anemometer, were used to measure wind speed and wind direction during the same period and in the near vicinity of one another.

The reference instrument measuring at 10-m height served two purposes. First, and most important, it served as a traditional, continuous wind measurement allowing a direct comparison with both the HWM and nearby DMI SYNOP stations. Second, it allowed us to investigate whether the use of roughness lengths derived from the HWMs leads to more accurate HWM-based estimates of 10-m wind speeds than using roughness lengths obtained from other sources. Extrapolating the HWM to the height of the reference observation thus gives an estimate of the quality of the derived roughness length from the HWM. The extrapolation is performed from about 
2 to $10 \mathrm{~m}$, both with stability correction (WSC) and no stability correction (NSC), using stability parameters from a short-term NWP model forecast. We touch on the importance of stability correction and parameters in section 3. In the rest of this section we describe in detail the various methods used in this paper. The methods are divided into four subsections, the wind measurement equipment (section 2a), the location of the measurement sites (section $2 b$ ), the NWP reference (section $2 c$ ), and the surface characteristics (section $2 \mathrm{~d}$ ) represented by the different sources of roughness lengths.

\section{a. Wind measurement equipment}

The HWMs were obtained with a Vaavud Sleipnir anemometer (Vaavud 2019) mounted on a smartphone with a dedicated Vaavud app running on the phone. This anemometer measures with a frequency of approximately $4 \mathrm{~Hz}$ and is designed to minimize the influence of flow distortion from the smartphone (A. Okholm 2016, personal communication). The $4-\mathrm{Hz}$ output from the Vaavud app is considered the measurement signal in this study. According to Vaavud, the anemometer is specified to work in the wind speed range from 2 to $40 \mathrm{~m} \mathrm{~s}^{-1}$ with $\pm 4 \%$ precision. Therefore, the observations should be used with caution in very low wind speeds. We note that the Sleipnir anemometer used in this study has been out of production since 2019. However, other manufacturers exist, such as Weatherflow (Weatherflow 2020). It was considered and suggested by one anonymous reviewer to further examine the anemometer performance (e.g., in a wind tunnel). Because of financial constraints, this was not possible.

Latitude and longitude are stored on the basis of the built-in smartphone Global Navigation Satellite System (GNSS) receiver position estimate. The GNSS receiver also returns altitude, but a comparison of 237 altitude estimates obtained in one session with the smartphone position fixed, showed that the GNSS altitude is currently not accurate enough for our purpose (the altitude estimates had a standard deviation of $20 \mathrm{~m}$ ). Instead, the height of the device above the ground was determined with a tape measure. It is noted though, that the accuracy of GNSS altitudes is expected to improve significantly in the future (Robustelli et al. 2019), to less than a meter in uncertainty. The duration of the HWM performed here is $30 \mathrm{~s}$, and the time of the measurement is defined as the time at the beginning of the measurement. An HWM was obtained approximately every $2 \mathrm{~min}$. Afterward, the individual HWMs were binned into intervals of $10 \mathrm{~min}$ for which the mean was computed.

The reference measurements were obtained with a high-precision ultrasonic anemometer (Gill Instruments 2017) placed $10 \mathrm{~m}$ above ground, on a thin mast stabilized against bending and undulation by three wires running from the top of the mast to spears in the ground. The 10-m height for traditional wind observations is based on guidelines by WMO (2008, chapter 5). The sampling frequency of the ultrasonic device was $1 \mathrm{~Hz}$. The accuracy is given by Gill Instruments (2017) as $\pm 2 \%$ at $12 \mathrm{~m} \mathrm{~s}^{-1}$. In one separate experiment the ultrasonic anemometer was placed at the same height as the HWM instrument to compare the two anemometers directly.

The minimum amount of metadata from the smartphone for an HWM to be considered valid was in this study defined as

1) the duration and measurement time of the HWM,

2) the latitude, longitude and the measurement height above ground, and

3) a device identification number.

Additional metadata were collected from other sources to assess the impact of using the roughness length derived from the HWMs and to examine the effects of the stability correction:

1) We looked at the characteristics of the surface in the form of roughness lengths from two different sources, used for comparison with the roughness length determined via the HWMs. In addition, the surface was characterized subjectively by the authors.

2) We looked at the lower tropospheric atmospheric stability (obtained here via an NWP model; see section 2c), used to examine the effects of stability corrections when extrapolating the HWM with height.

\section{b. Location of the measurement sites}

In total eight measurement sessions were carried out at three different locations: Hvide Sande (HVDS), Gniben (GNB), and Eskebjerg (ESKB), all in Denmark. Figure 1 shows satellite imagery of each location, plotted with the location of the reference measurement (red star) and the DMI SYNOP station (blue star). The locations and their coordinates are listed in Table 1. A summary of the prevailing weather conditions for each measurement session is given in Table 2. Six measurements sessions were done at ESKB and one at both HVDS and GNB. HVDS and GNB are locations with public access. Both are popular windsurfer spots, from which real user data will likely be available in the future. ESKB is a private area, which made it possible to make a more permanent installation of the measurement equipment.

HVDS is a beach location in western Denmark at the North Sea. The North Sea is to the west of HVDS, and to the east a fjord is present. The DMI station (HVDS DMI) is categorized as a coastal station (Cappelen 2012). 

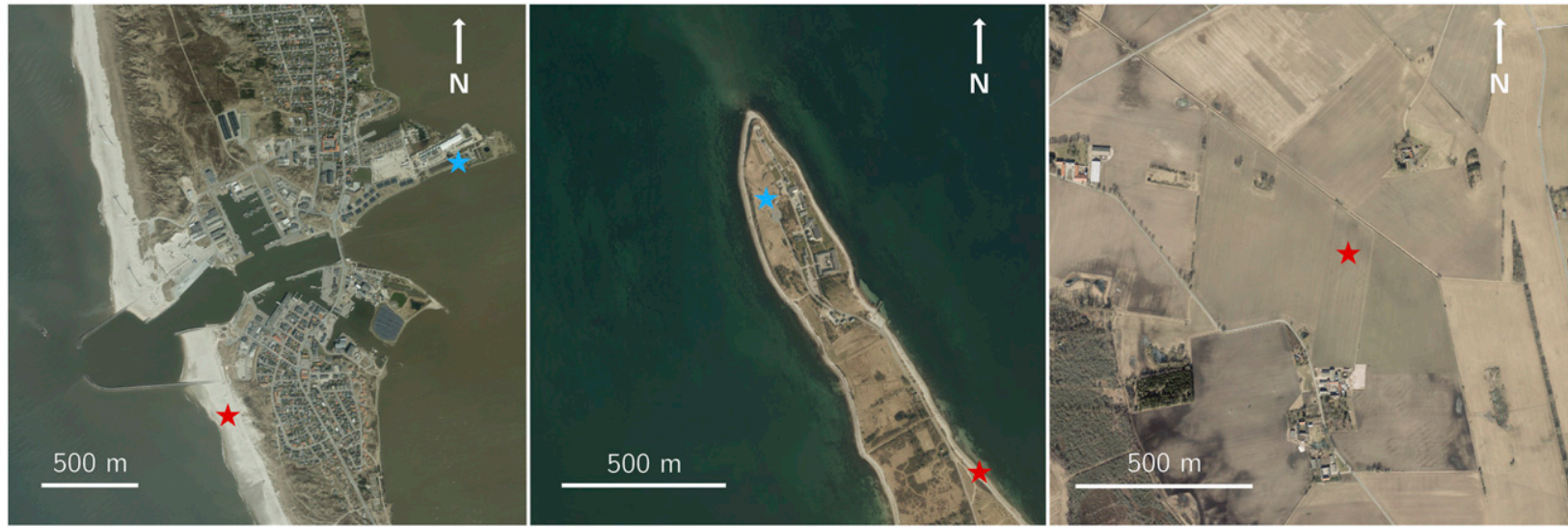

FIG. 1. Satellite imagery of the locations of the measurement sessions: (left) Hvide Sande (HVDS), (center) Gniben (GNB), and (right) Eskebjerg (ESKB). The red stars show the location of the reference measurement, and the blue stars show the locations of the DMI SYNOP stations.

However, HVDS DMI is located approximately $1.7 \mathrm{~km}$ inland, downstream of the prevailing wind direction (westerly onshore winds) in a small city. The HWMs and reference measurements were performed on the beach, upstream of the city, in westerly to southwesterly winds.

GNB is about $1 \mathrm{~km}$ from the tip of a long, narrow peninsula in central Denmark and is categorized as a coastal station (Cappelen 2012). The associated DMI SYNOP station (GNB DMI) is located about $1 \mathrm{~km}$ northwest of GNB, $200 \mathrm{~m}$ from the coastline, in a fenced military facility. The HWMs were performed within a few meters of the coastline in conditions with northeasterly onshore winds. GNB DMI is not placed optimally. Only $16 \mathrm{~m}$ south of the station is a military lattice tower with a height of $54 \mathrm{~m}$. To the east is a row of 2 -floor buildings, the closest one $44 \mathrm{~m}$ away, and to the north is a row of small buildings. There are no anthropogenic obstacles to the west. However, there is a steep hillside with a height of approximately $30 \mathrm{~m}$ leading up to the GNB DMI station about $80 \mathrm{~m}$ away. There is a slope all around the station, most prominent to the west.

ESKB is an inland location in eastern Denmark, about $4 \mathrm{~km}$ from the nearest coastline. ESKB can be considered to be open, agricultural terrain. The measurements were performed in wintertime when there were no crops in the fields. The nearest SYNOP station to ESKB is Holbaek, $20 \mathrm{~km}$ to the east and therefore the Holbaek DMI SYNOP cannot be seen in Fig. 1. The Holbaek DMI SYNOP is set up at a good location in open terrain with no disturbing objects close to the wind measurement. We consider the area of ESKB to be semismooth for most wind directions, with a few isolated obstacles. To the west are a few houses about $1.2 \mathrm{~km}$ away.

In all sessions but one, all smartphone measurements were performed by the first author to better control the measurement setup as compared with solely using real user data. In the HVDS session, measurements from kitesurfers standing on the beach nearby the reference anemometer are included. The height above ground of the surfer measurements is assumed to be $2 \mathrm{~m}$. The DMI SYNOP data are used for comparison and as an indicative, subjective measure of representativeness, an essential aspect when validating NWP models.

\section{c. References for stability correction}

To examine if extrapolation of the HWMs was improved by using stability correction or not (see section 3 ) stability parameters were obtained from a short-term NWP model forecast using the WRF Model (Skamarock et al. 2008; WRF V.3.9.1). From the WRF Model stability parameters such as the kinematic heat flux $H$ and the Obukhov length $L$ (see section 3 ) were obtained. The WRF Model was run with a horizontal resolution of $3 \mathrm{~km}$ and 30 vertical levels over the time period that the HWM measurements were available. The lowest model layer is $27 \mathrm{~m}$ above the surface and there are approximately 9 model layers in the boundary layer. The model was initiated from analysis data from NCEP (2000) every $6 \mathrm{~h}$. The surface-layer scheme used was the MM5 similarity scheme based on the Monin-Obukhov similarity

TABLE 1. Location of DMI SYNOP stations and sessions.

\begin{tabular}{lccc}
\hline \multicolumn{1}{c}{ Location } & Lat $\left({ }^{\circ} \mathrm{N}\right)$ & Lon $\left({ }^{\circ} \mathrm{E}\right)$ & No. of sessions \\
\hline Hvide Sande (HVDS) & 55.9951 & 8.1205 & 1 \\
Gniben (GNB) & 56.0004 & 11.2884 & 1 \\
Eskebjerg (ESKB) & 55.7037 & 11.2945 & 6 \\
HVDS DMI station & 56.0078 & 8.1413 & - \\
GNB DMI station & 56.0072 & 11.2800 & - \\
Holbaek DMI station & 55.7358 & 11.6035 & - \\
\hline
\end{tabular}


TABLE 2. Summarized weather conditions for each of the eight measurement sessions. T2m is the 2-m temperature from the nearest DMI SYNOP station. The wind conditions are summarized from the reference measurement and are given in meters per second, cloud cover is given in oktas when relevant, and $L^{-1}(\mathrm{NWP})$ and $L^{-1}(\mathrm{H} \& \mathrm{U})$ are the average reciprocal Obukhov lengths from NWP and the Holtslag and Van Ulden (1983) scheme, respectively.

\begin{tabular}{lccclcr}
\hline & Wind speed & Wind direction & T2m & \multicolumn{1}{c}{ Conditions } & $L^{-1}(\mathrm{NWP})$ & $L^{-1}(\mathrm{H} \& \mathrm{U})$ \\
\hline ESKB1 & $2-5$ & S-SW & $7^{\circ}-9^{\circ} \mathrm{C}$ & Haze, then clear & -0.28 & -0.90 \\
ESKB2 & $6-11$ & NW & $5^{\circ}-6^{\circ} \mathrm{C}$ & Scattered low clouds; $4 / 8$ & -0.02 & -0.02 \\
ESKB3 & $4-6$ & SW & $3^{\circ}-4^{\circ} \mathrm{C}$ & Few low clouds; $1 / 8$ & -0.04 & -0.07 \\
ESKB4 & $4-8$ & SW & $4^{\circ}-6^{\circ} \mathrm{C}$ & Scattered clouds; 3/8 & -0.08 & -0.29 \\
ESKB5 & $4-7$ & NE-ENE & $6^{\circ}-9^{\circ} \mathrm{C}$ & Clear & -0.41 & -1.79 \\
ESKB6 & $4-8$ & SW-W & $5^{\circ}-12^{\circ} \mathrm{C}$ & Fog, then clear 2017 \\
GNB & $8-11$ & E-SE & $10^{\circ}-11^{\circ} \mathrm{C}$ & Overcast; 8/8; drizzle & -0.04 & -0.16 \\
HVDS & $6-11$ & SW & $16^{\circ}-17^{\circ} \mathrm{C}$ & Few clouds; 2/8 & -0.39 & -0.24 \\
\hline
\end{tabular}

theory (Jiménez et al. 2012). The land surface scheme used was the Noah land surface model (Ek et al. 2003) and the boundary layer scheme was the Mellor-YamadaNakanishi-Niino (MYNN) 2.5 PBL scheme (Mellor and Yamada 1982). The model was initially stabilized with a digital filter (Lynch and Huang 1993) to prevent excitation of fast inertia-gravity waves and to reduce spinup time.

In addition surface fluxes were estimated from the nearest SYNOP station observations using the scheme of Holtslag and Van Ulden (1983), which might serve as an alternative to NWP stability estimates, as well as provide us with guidance toward the quality of the surface fluxes obtained with the WRF Model. The work of Holtslag and Van Ulden (1983) is an empirical scheme that estimates surface fluxes of heat and momentum using observations of total cloud cover, mean wind speed and air temperature. We note that the GNB DMI station does not have a ceilometer installed, for the GNB session, the total cloud cover was instead observed subjectively. For stability corrections our primary focus is on the NWP reference, as this is a more robust implementation in potential applications and have a much higher resolution than the SYNOP network, which has interstation distances of about $50 \mathrm{~km}$ and is irregular in aerial coverage across Denmark. However, we consider the Holtslag and Van Ulden scheme more consistent with the HWMs, as it also relies on observations and no NWP models are included. Table 2 summarizes the reciprocal Obukhov length scales for each measurement session for both NWP and the Holtslag and Van Ulden scheme.

\section{d. Surface characteristics}

The characteristics of the surface, in the form of roughness lengths, were determined quantitatively in three different ways:

One way is from the HWM using the measured horizontal turbulence intensity. The roughness lengths derived from the HWMs are denoted $z_{0}^{\mathrm{hwm}}$. The theory and uncertainties behind $z_{0}^{\text {hwm }}$ are presented in section 3 .
The NWP model is also used as a source of roughness lengths, denoted $z_{0}^{\text {nwp }}$. In the NWP model $z_{0}^{\text {nwp }}$ is derived from a table of land-use category, with a resolution of $30 \operatorname{arc~s}$ (approximately $1 \mathrm{~km}$ ) with a summer and winter value, upscaled to the gridbox resolution. The third and last source of roughness lengths is obtained from the work of Silva et al. (2007), who converted the Coordination of Information on the Environment (CORINE) land cover (CLC) 2000, version 18.5 (Buttner and Kosztra 2001), dataset, with a resolution of $100 \mathrm{~m}$, to a dataset of roughness lengths, here denoted $z_{0}^{\text {clc }}$. CLC is a widely used land surface dataset within geosciences delivered by the Copernicus Land Monitoring Service. In addition the surface characteristics were determined subjectively by the authors.

The extrapolated HWMs are denoted on the basis of the source of roughness length that has been used as $u_{\mathrm{nwp}}^{10 \mathrm{~m}}, u_{\mathrm{clc}}^{10 \mathrm{~m}}$, and $u_{\mathrm{hwm}}^{10 \mathrm{~m}}$. The HWMs that have not been extrapolated are denoted $u_{\mathrm{hwm}}^{s}$ using $s$ for surface. The reference is denoted $u_{\mathrm{ref}}^{10 \mathrm{~m}}$, and the wind observations from the DMI SYNOP stations are denoted $u_{\mathrm{dmi}}^{10 \mathrm{~m}}$. The raw HWMs that have not been averaged over time are denoted $u_{\text {raw }}$.

\section{Theory}

The roughness length can be estimated from wind measurements by considering the horizontal turbulent intensity (Counihan 1975). The idea is that for a given wind speed, a rough surface will generate more turbulence near the ground than a smooth surface. Following Counihan the roughness length can be estimated as

$$
z_{0}^{\mathrm{hwm}}=A z \exp \left[-u(z) / \sigma_{u}\right],
$$

where $\sigma_{u}$ is the standard deviation of the wind measurement, $u(z)$ is the mean wind speed over an appropriate averaging time at height $z$, and $A=\left(\sigma_{u} / u_{*}\right) k$, with $u_{*}$ being the friction velocity and $k$ being the von Kármán constant $(k=0.4)$. The $\sigma_{u} / u(z)$ represents the horizontal turbulent intensity. Equation (1) is derived 
from the logarithmic wind profile [see Eq. (4), below] as based on the assumption that $\sigma_{u} / u_{*}=2.5$ (Arya 1995) such that $A=1$. It is noted that this relation is valid only at neutral stability. In practice, stability effects can alter the interpretation of the results and must be acknowledged as a source of error. Here, we have not considered this effect. A measurement with a handheld anemometer at about $2 \mathrm{~m}$ will often be influenced by upstream local effects, so this approach can only be assumed valid for smooth terrain $\left(z_{0}<0.1 \mathrm{~m}\right)$. Equation (1) implies that for a constant roughness length the ratio $u(z) / \sigma_{u}$ must also be constant, since $A$ and the measurement height $z$ are constants. The ratio $u(z) / \sigma_{u}$ has been smoothed by convolving the time series with a Gaussian kernel using a standard deviation of 5 so that weights are decreased farther away from the target value.

The wind speed increases considerably with height near the surface due to surface friction making $z_{0}$ an essential parameter for extrapolation of wind measurements. Therefore, by extrapolating the HWMs, one can test the quality of the roughness lengths. To extrapolate the HWMs two approaches were used, based on the logarithmic wind profile law with and without stability correction (WSC and NSC, respectively). Based on the Monin-Obukhov similarity theory (Monin and Obukhov 1954), it follows that the nondimensional vertical mean wind speed gradient $[\phi(z / L)]$ is given by

$$
\phi\left(\frac{z}{L}\right)=\frac{k z}{u_{*}} \frac{\partial u}{\partial z}
$$

with $z$ being the height above the surface and $L$ being the Obukhov length given by $L=-u_{*}^{3} c_{p} \rho T /(k g H)$, where
$H /\left(\rho c_{p}\right)$ is the kinematic heat flux, $g$ is the gravitational acceleration, and $T$ is the absolute temperature. Quantities $L$ and $H$ were determined from the NWP model described in section 2c. The $\phi(z / L)$ has been determined empirically for unstable $(z / L<0)$ and stable $(z / L>0)$ conditions as (Businger et al. 1971)

$$
\phi(z / L)=\left\{\begin{array}{ll}
1+\beta_{1} \frac{z}{L} & \text { if } \quad z / L \geq 0 \\
\left(1-\gamma_{1} z / L\right)^{-1 / 4} & \text { if } \quad z / L<0
\end{array},\right.
$$

where $\beta_{1}$ and $\gamma_{1}$ are empirical constants. Discrepancies do exist in the chosen values for these constants. Here $\beta_{1}=5$ is used on the basis of the argumentation of supercritical flux Richardson numbers by Kouznetsov and Zilitinkevich (2010), and $\gamma_{1}=15$ following Arya (2001).

Integrating Eq. (2) from $z_{0}$ to $z$, using $u\left(z_{0}\right)=0$, yields (Panofsky 1963)

$$
u(z)=\frac{u_{*}}{k}\left[\ln \frac{z}{z_{0}}-\psi(z / L)\right],
$$

where

$$
\psi(z / L)=\int_{z_{0}}^{z}[1-\phi(z / L)] d z
$$

For $z / L=0$, which is neutral conditions, Eq. (4) reduces to the logarithmic wind profile law $(\phi(z / L)=1$, e.g., the case of NSC), which can typically be obtained in cases with strong winds and overcast skies. Panofsky (1963) and Paulson (1970) gives the solution for $\psi(z / L)$ for the stable $(z / L \geq 0)$ and unstable $(z / L<0)$ case, respectively, as

$$
\psi(z / L)= \begin{cases}-\beta_{1} \frac{z}{L} & \text { for } \quad z / L \geq 0 \\ \ln \left[\left(\frac{1+x}{2}\right)^{2}\left(\frac{1+x^{2}}{2}\right)\right]-2 \tan ^{-1}(x)+(\pi / 2) & \text { for } z / L<0\end{cases}
$$

where $x=\left(1-\gamma_{1} z / L\right)^{1 / 4}$. Now let $u\left(z_{2}\right)$ be the extrapolated wind measurement and let $u\left(z_{1}\right)$ be the HWM, where $z_{2}>z_{1}$. Assuming that $z_{2}$ and $z_{1}$ are located in the same internal boundary layer (IBL) one can solve for $u\left(z_{2}\right)$ by using Eq. (4) to obtain an expression for $u\left(z_{1}\right)$ and $u\left(z_{2}\right)$ and dividing them with each other to obtain

$$
u\left(z_{2}\right)=\frac{\ln z_{2} / z_{0}-\psi_{2}\left(z_{2} / L\right)}{\ln z_{1} / z_{0}-\psi_{1}\left(z_{1} / L\right)} u\left(z_{1}\right),
$$

using Eq. (5) for the stable and unstable cases, respectively. Equation (6) then represents an approach to extrapolate a wind measurement in the surface layer, correcting for stability (WSC), using $z_{0}$ as a parameter. Setting $\psi=0$ corresponds to the case of NSC.

\section{Results}

First, as mentioned in section 2, the handheld anemometer and the ultrasonic anemometer was in one separate experiment placed at the same height to compare them directly. They were placed at $2.2-\mathrm{m}$ height above the surface, $1 \mathrm{~m}$ apart in the horizontal. Both devices were measuring continuous for $8 \mathrm{~h}$. The mean 
wind speed in the period from the ultrasonic anemometer was $4.00 \mathrm{~m} \mathrm{~s}^{-1}$. A net positive bias amounted to $0.05 \mathrm{~m} \mathrm{~s}^{-1}$ for the HWM relative to the ultrasonic anemometer. The $z_{0}$ was in this case calculated on the basis of both the handheld anemometer and the ultrasonic reference measurement. For the handheld device, $z_{0}^{\text {hwm }}=1.5 \times 10^{-2} \pm 0.3 \times 10^{-2} \mathrm{~m}$; for the reference measurement, $z_{0}^{\mathrm{ref}}=1.0 \times 10^{-2} \pm 0.2 \times 10^{-2} \mathrm{~m}$, where the uncertainty is given as 1 standard deviation of the mean.

Figure 2 shows the time series of wind measurements for ESKB4 starting on 0530 UTC 3 March. As described, the mean HWMs was extrapolated to $10 \mathrm{~m}$ using roughness lengths of different origin, $z_{0}^{\text {nwp }}, z_{0}^{\mathrm{clc}}$, and $z_{0}^{\text {hwm }}$, all with NSC. For this case $z_{0}^{\text {nwp }}=0.06 \mathrm{~m}, z_{0}^{\text {clc }}=0.10 \mathrm{~m}$, and $z_{0}^{\mathrm{hwm}}=0.003 \mathrm{~m}$ (see Table 3 ). Note that $z_{0}^{\text {clc }}$ is constant for each location. The bias of the extrapolated wind speed relative to the reference anemometer is lowest for $u_{\mathrm{hwm}}^{10 \mathrm{~m}}$ NSC with $0.27 \mathrm{~m} \mathrm{~s}^{-1}$. The difference in bias between using stability correction (WSC) or not (NSC) for $u_{\mathrm{hwm}}^{10 \mathrm{~m}}$ is only $0.05 \mathrm{~m} \mathrm{~s}^{-1}$ for this case. For $u_{\mathrm{nwp}}^{10 \mathrm{~m}} \mathrm{NSC}$ the net bias is $1.57 \mathrm{~m} \mathrm{~s}^{-1}$, and for $u_{\mathrm{clc}}^{10 \mathrm{~m}} \mathrm{NSC}$ the net bias is $2.08 \mathrm{~m} \mathrm{~s}^{-1}$. In this case, $u_{\mathrm{hwm}}^{10 \mathrm{~m}}$ performs best with regard to both bias and root-mean-square error (RMSE) for both NSC and WSC.

One example with a large difference between using stability correction (WSC) or not using it (NSC) (see Fig. 3) was found for $u_{\mathrm{nwp}}^{10 \mathrm{~m}}$ using ESKB5 measurements, where both extrapolations used $z_{0}^{\text {nwp }}=0.05 \mathrm{~m}$. The RMSEs for $u_{\mathrm{nwp}}^{10 \mathrm{~m}}$ WSC and NSC were 1.03 and $1.43 \mathrm{~m} \mathrm{~s}^{-1}$, respectively. However, no clear trend in the data of RMSE with regard of using NSC or WSC is visible in general, other than that the difference of using stability correction or not is relatively small (see Table 3). In the cases of ESKB1, ESKB3, and ESKB4 the RMSE and bias of $u^{10 \mathrm{~m}}$ are higher for WSC than for NSC. The opposite is seen for ESKB2, ESKB5, and ESKB6 where the RMSE and bias are lower for WSC than for NSC.

It is noted that the wind direction is similar for ESKB1, ESKB3, and ESKB4 (southwesterly winds), whereas for ESKB6 the wind is slightly more westerly and for ESKB2 and ESKB4 the wind is more northerly. The variation in RMSE with and without stability correction may relate directly to the land surface model of the NWP model, as this can affect the stability in the model, but it is unknown to what extent this is the case.

Figure 4 shows the measurement session for GNB. We find that $u_{\mathrm{clc}}^{10 \mathrm{~m}}$ is performing worse than both $u_{\mathrm{hwm}}^{10 \mathrm{~m}}$ and $u_{\mathrm{nwp}}^{10 \mathrm{~m}}$. RMSE and bias for $u_{\mathrm{hwm}}^{10 \mathrm{~m}}$ improved for WSC relative to NSC, decreasing from 0.87 and $0.43 \mathrm{~m} \mathrm{~s}^{-1}$, respectively, to 0.74 and $0.13 \mathrm{~m} \mathrm{~s}^{-1}$ (see Table 3 ). In the case of GNB all errors in general decrease when correcting for stability.

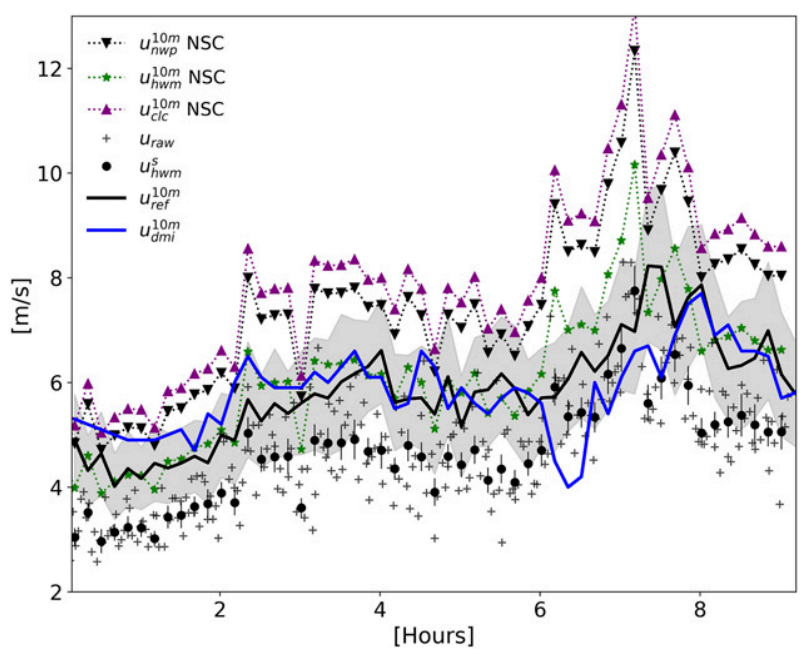

FIG. 2. Time series of wind measurements at Eskebjerg starting 0530 UTC 3 Mar 2017 (ESKB4). The abscissa shows hours since the beginning of measurements, and the ordinate shows wind speed $\left(\mathrm{m} \mathrm{s}^{-1}\right)$. Black crosses show individual handheld measurements $u_{\text {raw }}$, and solid black circles show the average within $10 \min u_{\mathrm{hwm}}^{s}$. The gray shaded area shows the standard deviation of $u_{\mathrm{ref}}^{10 \mathrm{~m}}$. The black curve gives $u_{\mathrm{ref}}^{10 \mathrm{~m}}$, the blue curve gives $u_{\mathrm{dmi}}^{10 \mathrm{~m}}$ from Holbaek, the purple dotted curve gives $u_{\text {clc }}^{10 \mathrm{~m}} \mathrm{NSC}$, the green dotted curve gives $u_{\mathrm{hwm}}^{10 \mathrm{~m}}$ NSC, and the black dotted curve gives $u_{\mathrm{nwp}}^{10 \mathrm{~m}}$ NSC.

Unlike the measurements at ESKB and GNB, the session at HVDS is the only one including measurements obtained by ordinary users, using their own equipment in connection with a kitesurfing competition in September 2016. This dataset is a mix of measurements from several different smartphones and several different Vaavud anemometers. From Fig. 5, showing the HVDS observations, we find that the HWMs appear more irregular when compared with ESKB measurements in Figs. 2 and 3. All measurements are taken onshore spreading $200 \mathrm{~m}$ north and south of the reference $10-\mathrm{m}$ measurement, within $50 \mathrm{~m}$ from the coastline, and with onshore wind. In this case, $u_{\mathrm{hwm}}^{10 \mathrm{~m}}$ has the highest RMSE in total with $1.49 \mathrm{~m} \mathrm{~s}^{-1}$ with NSC. The DMI observations are also shown in Fig. 5. The RMSE of $u_{\mathrm{dmi}}^{10 \mathrm{~m}}$ is $3.00 \mathrm{~m} \mathrm{~s}^{-1}$, almost $2 \mathrm{~m} \mathrm{~s}^{-1}$ higher than for the HWMs.

We show in section 3 that for $z_{0}^{\text {hwm }}$ to be constant, the ratio $u(z) / \sigma_{u}$ must also be constant. $u(z) / \sigma_{u}$ is plotted with wind speed and wind direction in Fig. 6 for ESKB5. This plot was chosen because during this session the biggest changes in wind conditions was seen. The wind speed increased from about 3 to $7 \mathrm{~m} \mathrm{~s}^{-1}$; also a small change in wind direction is seen. The ratio $u(z) / \sigma_{u}$ is relatively constant during the increase and decrease in wind speed. However, there is a large spread in especially the handheld measurements. Convolving the time series with a Gaussian kernel (black lines in Fig. 6) helps to define a general trend in both the case of the reference and the 
TABLE 3. Table of root-mean-square (RMS) errors and bias of the measured wind speed $u$, relative to the reference observation at $10 \mathrm{~m}$. HVDS is Hvide Sande, GNB is Gniben, and ESKB is Eskebjerg. WSC indicates with stability correction. NSC indicates no stability correction. All numbers are in meters per second unless otherwise stated. The $z_{0}$ of $u_{\mathrm{ref}}^{10 \mathrm{~m}}$ is the roughness length obtained from the reference observation using the same method as with $z_{0}^{\mathrm{hwm}}$. The number of measurements in each session is specified by $N$ in parentheses. The $\overline{\left(\mathbf{u} / \sigma_{\mathbf{u}}\right)}$ is the average turbulent intensity, and $\sigma\left(\mathbf{u} / \boldsymbol{\sigma}_{\mathbf{u}}\right)$ is the standard deviation of the turbulent intensity. For each session, the lowest RMS and bias have been indicated with boldface numbers and the highest errors have been indicated with italic numbers.

\begin{tabular}{|c|c|c|c|c|c|c|c|c|c|c|}
\hline & RMS NSC & RMS WSC & BIAS NSC & BIAS WSC & $z_{0}(\mathrm{~m})$ & & RMS & BIAS & $\overline{\left(\mathbf{u} / \sigma_{\mathbf{u}}\right)}$ & $\sigma\left(\mathbf{u} / \boldsymbol{\sigma}_{\mathbf{u}}\right)$ \\
\hline \multicolumn{11}{|c|}{ ESKB1 ( $N: 108)$} \\
\hline$u_{\mathrm{nwp}}^{10 \mathrm{~m}}$ & 0.78 & 1.18 & 0.29 & 0.84 & 0.086 & $u_{\mathrm{dmi}}^{10 \mathrm{~m}}$ & 0.73 & -0.47 & - & - \\
\hline$u_{\mathrm{clc}}^{10 \mathrm{~m}}$ & 0.82 & 1.25 & 0.35 & 0.90 & 0.100 & $u_{\mathrm{hwm}}^{s}$ & 0.89 & -0.73 & 7.57 & 1.28 \\
\hline$u_{\mathrm{hwm}}^{10 \mathrm{~m}}$ & 0.61 & 0.68 & -0.15 & 0.19 & 0.008 & $u_{\mathrm{ref}}^{10 \mathrm{~m}}$ & - & - & 6.48 & 0.26 \\
\hline$u_{\mathrm{ref}}^{10 \mathrm{~m}}$ & - & - & - & - & 0.031 & & & & & \\
\hline \multicolumn{11}{|c|}{$\operatorname{ESKB} 2(N: 271)$} \\
\hline$u_{\mathrm{nwp}}^{10 \mathrm{~m}}$ & 2.06 & 1.97 & 1.66 & 1.57 & 0.050 & $u_{\mathrm{dmi}}^{10 \mathrm{~m}}$ & 1.96 & 1.68 & - & - \\
\hline$u_{\mathrm{clc}}^{10 \mathrm{~m}}$ & 2.92 & 2.80 & 2.58 & 2.48 & 0.100 & $u_{\mathrm{hwm}}^{s}$ & 2.05 & -1.78 & 4.97 & 0.52 \\
\hline$u_{\mathrm{hwm}}^{10 \mathrm{~m}}$ & 1.48 & 1.42 & 0.97 & 0.90 & 0.022 & $u_{\mathrm{ref}}^{10 \mathrm{~m}}$ & - & - & 5.97 & 0.35 \\
\hline$u_{\mathrm{ref}}^{10 \mathrm{~m}}$ & - & - & - & - & 0.038 & & & & & \\
\hline \multicolumn{11}{|c|}{$\operatorname{ESKB} 3(N: 134)$} \\
\hline$u_{\mathrm{nwp}}^{10 \mathrm{~m}}$ & 1.05 & 1.3 & 0.76 & 1.03 & 0.050 & $u_{\mathrm{dmi}}^{10 \mathrm{~m}}$ & 4.42 & 4.26 & - & - \\
\hline$u_{\mathrm{clc}}^{10 \mathrm{~m}}$ & 1.51 & 1.84 & 1.26 & 1.59 & 0.100 & $u_{\mathrm{hwm}}^{s}$ & 1.24 & -1.14 & 6.51 & 0.52 \\
\hline$u_{\mathrm{hwm}}^{10 \mathrm{~m}}$ & 0.67 & 0.82 & 0.26 & 0.47 & 0.017 & $u_{\mathrm{ref}}^{10 \mathrm{~m}}$ & - & - & 6.20 & 0.47 \\
\hline$u_{\mathrm{ref}}^{10 \mathrm{~m}}$ & - & - & - & - & 0.026 & & & & & \\
\hline \multicolumn{11}{|c|}{ ESKB4 (N: 274) } \\
\hline$u_{\mathrm{nwp}}^{10 \mathrm{~m}}$ & 1.86 & 1.92 & 1.57 & 1.66 & 0.060 & $u_{\mathrm{dmi}}^{10 \mathrm{~m}}$ & 0.79 & 0.01 & - & - \\
\hline$u_{\mathrm{clc}}^{10 \mathrm{~m}}$ & 2.36 & 2.43 & 2.08 & 2.18 & 0.100 & $u_{\mathrm{hwm}}^{s}$ & 1.27 & -1.12 & 7.37 & 0.40 \\
\hline$u_{\mathrm{hwm}}^{10 \mathrm{~m}}$ & 0.81 & 0.82 & 0.27 & 0.32 & 0.033 & $u_{\mathrm{ref}}^{10 \mathrm{~m}}$ & - & - & 5.79 & 0.20 \\
\hline$u_{\mathrm{ref}}^{10 \mathrm{~m}}$ & - & - & - & - & 0.035 & & & & & \\
\hline \multicolumn{11}{|c|}{ ESKB5 (N: 307) } \\
\hline$u_{\mathrm{nwp}}^{10 \mathrm{~m}}$ & 1.43 & 1.03 & 1.21 & 0.88 & 0.050 & $u_{\mathrm{dmi}}^{10 \mathrm{~m}}$ & 1.96 & -1.7 & - & - \\
\hline$u_{\mathrm{clc}}^{10 \mathrm{~m}}$ & 1.78 & 1.34 & 1.56 & 1.19 & 0.100 & $u_{\mathrm{hwm}}^{s}$ & 0.68 & -0.61 & 9.81 & 1.02 \\
\hline$u_{\mathrm{hwm}}^{10 \mathrm{~m}}$ & 0.59 & 0.38 & 0.34 & 0.14 & 0.020 & $u_{\mathrm{ref}}^{10 \mathrm{~m}}$ & - & - & 8.09 & 0.91 \\
\hline$u_{\mathrm{ref}}^{10 \mathrm{~m}}$ & - & - & - & - & 0.015 & & & & & \\
\hline \multicolumn{11}{|c|}{ ESKB6 ( $N: 221)$} \\
\hline$u_{\mathrm{nwp}}^{10 \mathrm{~m}}$ & 2.01 & 1.79 & 1.80 & 1.59 & 0.080 & $u_{\mathrm{dmi}}^{10 \mathrm{~m}}$ & 4.57 & 4.38 & - & - \\
\hline$u_{\mathrm{clc}}^{10 \mathrm{~m}}$ & 2.20 & 1.97 & 1.99 & 1.76 & 0.100 & $u_{\mathrm{hwm}}^{s}$ & 0.83 & -0.69 & 8.02 & 0.49 \\
\hline$u_{\mathrm{hwm}}^{10 \mathrm{~m}}$ & 0.88 & 0.78 & 0.57 & 0.45 & 0.003 & $u_{\mathrm{ref}}^{10 \mathrm{~m}}$ & - & - & 5.95 & 0.35 \\
\hline$u_{\mathrm{ref}}^{10 \mathrm{~m}}$ & - & - & - & - & 0.034 & & & & & \\
\hline \multicolumn{11}{|c|}{ GNB $(N: 185)$} \\
\hline$u_{\mathrm{nwp}}^{10 \mathrm{~m}}$ & 0.73 & 0.71 & 0.12 & -0.13 & 0.0003 & $u_{\mathrm{dmi}}^{10 \mathrm{~m}}$ & 2.58 & -2.03 & - & - \\
\hline$u_{\mathrm{clc}}^{10 \mathrm{~m}}$ & 4.48 & 3.68 & 4.23 & 3.44 & 0.200 & $u_{\mathrm{hwm}}^{s}$ & 1.51 & -1.36 & 9.28 & 1.26 \\
\hline$u_{\mathrm{hwm}}^{10 \mathrm{~m}}$ & 0.87 & 0.74 & 0.43 & 0.13 & 0.001 & $u_{\mathrm{ref}}^{10 \mathrm{~m}}$ & - & - & 10.75 & 0.40 \\
\hline$u_{\mathrm{ref}}^{10 \mathrm{~m}}$ & - & - & - & - & 0.0001 & & & & & \\
\hline \multicolumn{11}{|c|}{ HVDS ( $N: 216)$} \\
\hline$u_{\mathrm{nwp}}^{10 \mathrm{~m}}$ & 0.67 & 0.60 & 0.38 & 0.25 & 0.0001 & $u_{\mathrm{dmi}}^{10 \mathrm{~m}}$ & 3.00 & -2.42 & - & - \\
\hline$u_{\mathrm{clc}}^{10 \mathrm{~m}}$ & 0.71 & 0.64 & 0.45 & 0.32 & 0.0003 & $u_{\mathrm{hwm}}^{s}$ & 1.06 & -0.91 & 9.97 & 0.80 \\
\hline$u_{\mathrm{hwm}}^{10 \mathrm{~m}}$ & 1.49 & 1.31 & 1.34 & 1.13 & 0.010 & $u_{\mathrm{ref}}^{10 \mathrm{~m}}$ & - & - & 11.76 & 0.63 \\
\hline$u_{\mathrm{ref}}^{10 \mathrm{~m}}$ & - & - & - & - & 0.0009 & & & & & \\
\hline
\end{tabular}

handheld measurements. The standard deviation for all $u(z) / \sigma_{u}$-ratios is shown in the rightmost column in Table 3.

The RMSE and bias relative to the $10 \mathrm{~m}$ reference measurement, $u_{\mathrm{ref}}^{10 \mathrm{~m}}$, are calculated for each method on each location (see Fig. 7 and in Table 3). The biases of $u_{\mathrm{hwm}}^{s}$ are all negative. This can be explained by $u_{\mathrm{hwm}}^{s}$ being measured closer to the surface than the reference, hence the wind speed is in general lower. Because all extrapolations are performed the same way, the only difference being the roughness length, the differences in 


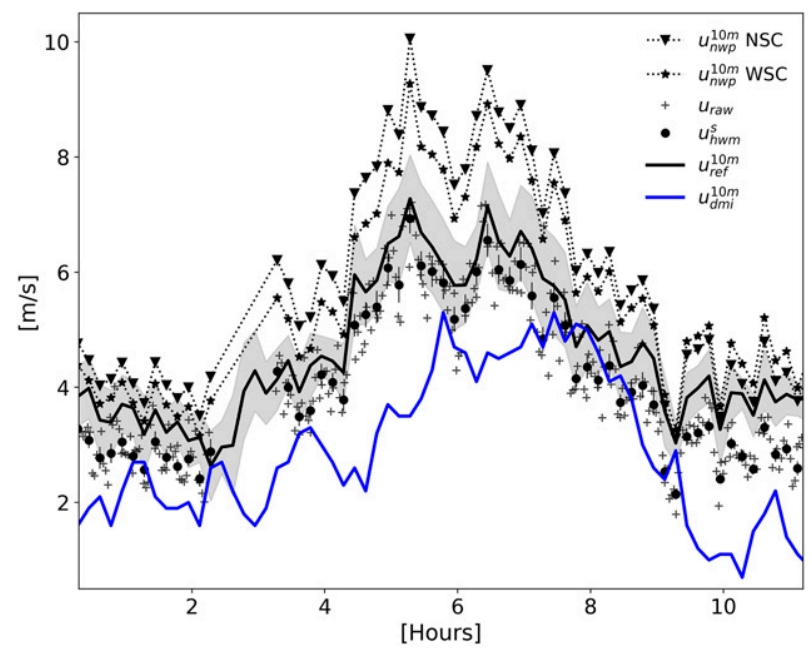

FIG. 3. As in Fig. 2, but starting at 0820 UTC 23 Mar 2017 (ESKB5).

The black dashed curves give $u_{\mathrm{nwp}}^{10 \mathrm{~m}}$ NSC and WSC, as labeled.

RMSE and bias between the HWMs are all due to differences of the roughness lengths. $u_{\mathrm{dmi}}^{10 \mathrm{~m}}$ in Fig. 7 (red bars) shows the RMSE and bias from the nearest DMI SYNOP station relative to $u_{\mathrm{ref}}^{10 \mathrm{~m}}$. Recall that for the ESKB location the nearest DMI station is about $20 \mathrm{~km}$ away, whereas for GNB and HVDS they are of order $1 \mathrm{~km}$ away. The RMSE and bias of both, the extrapolated handheld 10-m wind estimates and $u_{\mathrm{hwm}}^{s}$ at GNB and HVDS locations, are all lower than for $u_{\mathrm{dmi}}^{10 \mathrm{~m}}$ at these locations. Also, it is seen that $u_{\mathrm{clc}}^{10 \mathrm{~m}}$ WSC and NSC gives worse results than $u_{\mathrm{hwm}}^{s}$ and $u_{\mathrm{dmi}}^{10 \mathrm{~m}}$.

Table 4 shows the total RMSE and average bias for the case of NSC, WSC and stability correction using surface fluxes from the Holtslag and Van Ulden (1983) scheme (see section 2c). In these cases the Holtslag and

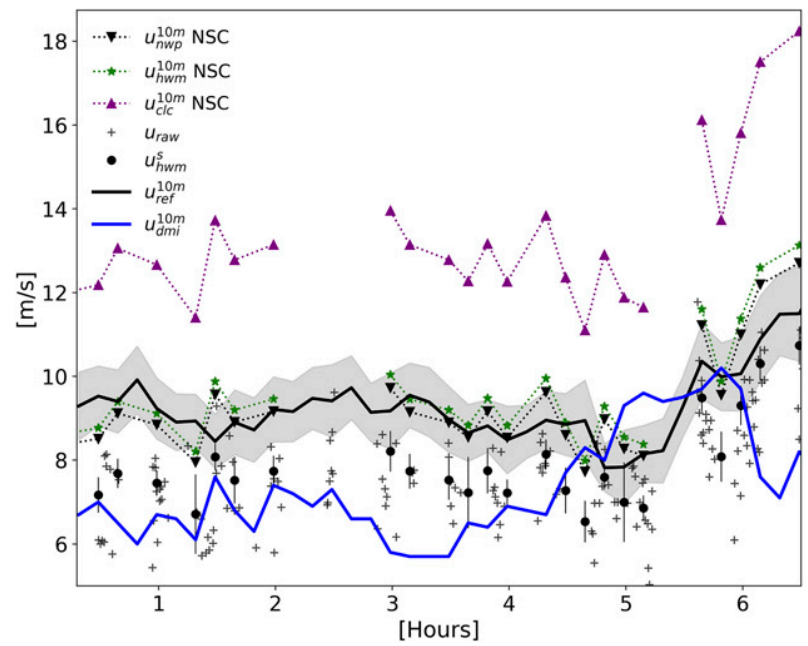

FIG. 4. As in Fig. 2, but at Gniben starting 0800 UTC 13 Oct 2016 (GNB). $u_{\mathrm{ref}}^{10 \mathrm{~m}}$. The blue curve gives $u_{\mathrm{dmi}}^{10 \mathrm{~m}}$ from Gniben.

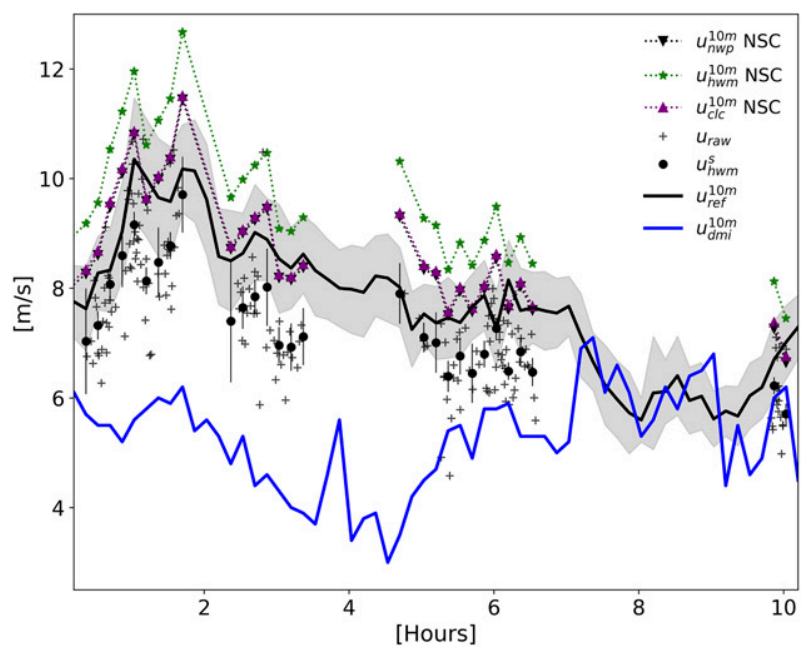

FIG. 5. As in Fig. 2, but at Hvide Sande starting at 0710 UTC 3 Sep (HVDS). The blue curve gives $u_{\mathrm{dmi}}^{10 \mathrm{~m}}$ from Hvide Sande.

Van Ulden (1983) scheme gives the best results overall, with both lower RMSE and bias compared to the case of NSC and WSC. Dividing the results based on the measurement location, we see that the RMSE and bias using the Holtslag and Van Ulden scheme does in general increase when the SYNOP station is farther away while there is no such tendency for the NWP method.

Overall, it is difficult to conclude whether $u_{\mathrm{nwp}}^{10 \mathrm{~m}}$ or $u_{\mathrm{hwm}}^{10 \mathrm{~m}}$ is the better choice in general, since at ESKB the RMSE and bias are lower for $u_{\mathrm{hwm}}^{10 \mathrm{~m}}$, while at GNB and HDVS

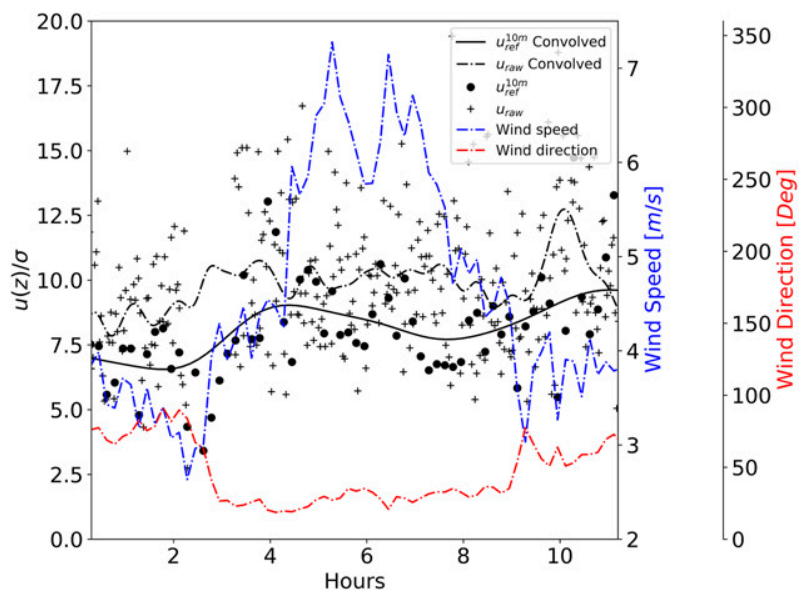

FIG. 6. Time series of wind measurements at Eskebjerg starting at 0820 UTC 23 Mar 2017 (ESKB5). The abscissa gives hours since the beginning of measurements, the left ordinate gives the ratio of $u(z) / \sigma_{u}$, and the right ordinate gives wind speed (blue) and direction (red) from 10-m reference observations. The black dots and crosses show the ratio $u(z) / \sigma_{u}$ from the reference measurements and the handheld measurements, respectively. The solid and dashed black lines show the convolved measurements, using a Gaussian filter, from the reference and the handheld measurements, respectively. 

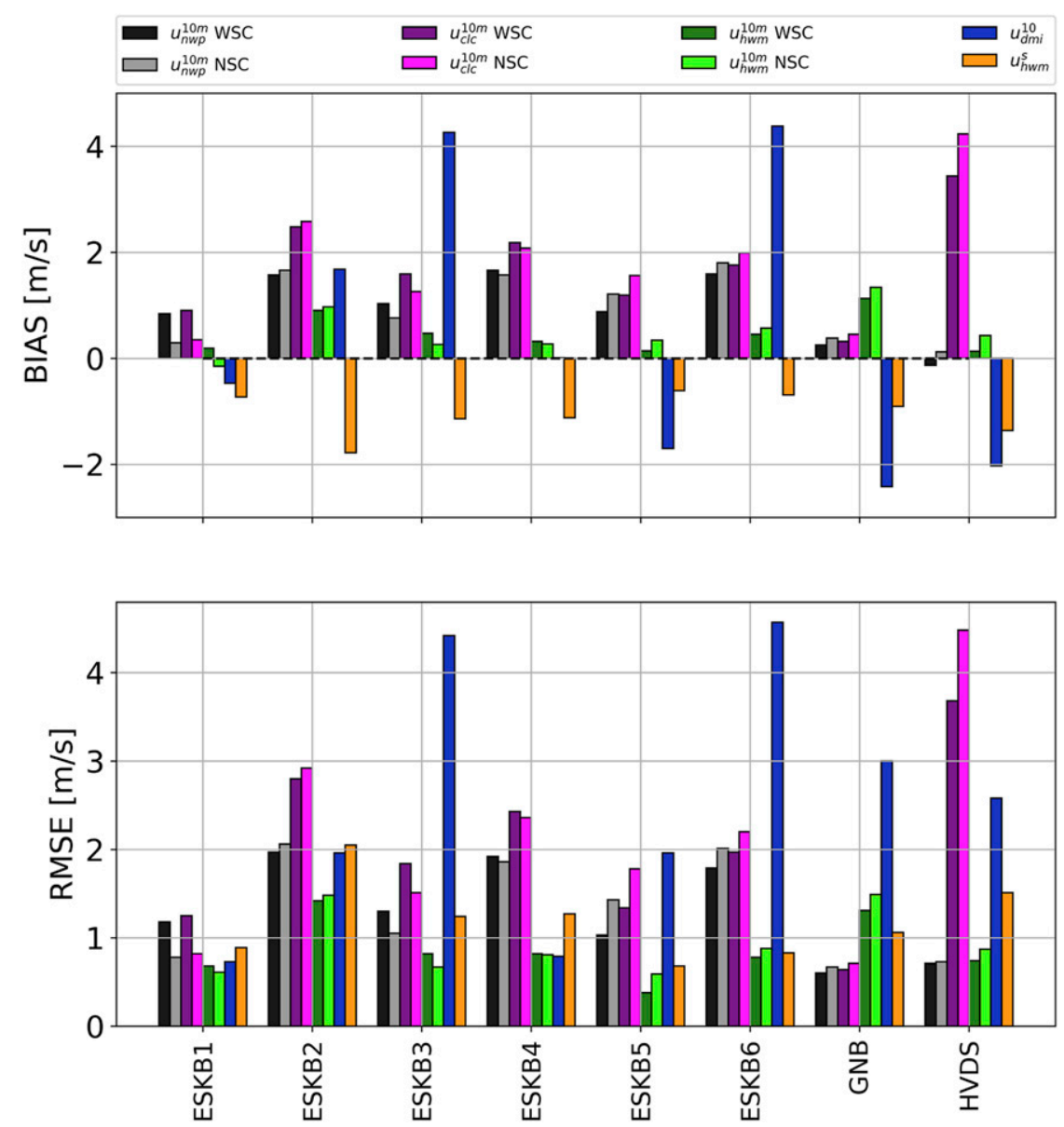

FIG. 7. (bottom) RMSE and (top) bias, with the abscissa giving the names of the locations. The "truth" is the reference observation at $10 \mathrm{~m} u_{\mathrm{ref}}^{10 \mathrm{~m}} ; u_{\mathrm{dmi}}^{10 \mathrm{~m}}$ (blue bars) and $u_{\mathrm{hwm}}^{s}$ (orange bars) are the nearest SYNOP station and the handheld observations, respectively. The other bars, labeled in the legend at the top, are the extrapolated winds using roughness lengths of different origin.

they are lower for $u_{\mathrm{nwp}}^{10 \mathrm{~m}}$. However, $u_{\mathrm{nwp}}^{10 \mathrm{~m}}$ and $u_{\mathrm{hwm}}^{10 \mathrm{~m}}$ both clearly outperformed $u_{\mathrm{clc}}^{10 \mathrm{~m}}$.

\section{Discussion}

It is found that the stability correction does not play a vital role in any of the cases studied here, and it has no clear trends when considering the RMSE of NSC and WSC in Table 3. One should recall that Eq. (1) does not take into account stability effects, hence $Z_{0}^{\text {hwm }}$ assumes neutral conditions. Similarly neither $z_{0}^{\text {nwp }}$ or $z_{0}^{\text {clc }}$ considers stability effects. Table 2 shows that in most cases the low atmosphere was actually moderately unstable. However, comparing 10-m wind speeds derived using $z_{0}^{\mathrm{hwm}}, z_{0}^{\mathrm{nwp}}$, and $z_{0}^{\text {clc }}$ we see that despite this, the results are very good for $Z_{0}^{\text {hwm }}$ (see Table 3).

We notice that the stability correction is prone to errors of the numerical forecast model, which can alter the interpretation of the results. Other measures of atmospheric stability could be used. Here we have as described, also used the method suggested by Holtslag and Van Ulden (1983). It should be noted that SYNOP observations of total cloud cover vary significantly in quality, and that many SYNOP sites do not report cloud

TABLE 4. Table of total RMS errors and average bias of extrapolations of wind using no stability correction (NSC), using stability correction with NWP estimates of surface fluxes (WSC), and stability correction using the Holtslag and Van Ulden (1983) scheme. All numbers are in meters per second.

\begin{tabular}{lccccccc}
\hline \hline & \multicolumn{3}{c}{ RMS } & & \multicolumn{3}{c}{ Bias } \\
\cline { 2 - 5 } \cline { 7 - 8 } & $z_{0}^{\text {nwp }}$ & $z_{0}^{\text {ti }}$ & $z_{0}^{\text {clc }}$ & & $z_{0}^{\text {nwp }}$ & $z_{0}^{\text {ti }}$ & $z_{0}^{\text {clc }}$ \\
\hline NSC & 1.44 & 0.99 & 2.39 & & 0.98 & 0.50 & 1.81 \\
WSC & 1.40 & 0.92 & 2.19 & & 0.96 & 0.47 & 1.74 \\
Holtslag and Van Ulden & 1.08 & 0.74 & 1.86 & & 0.43 & -0.03 & 1.24 \\
\hline
\end{tabular}


cover. Of the tree SYNOP stations considered here, only two have a ceilometer installed, HVDS DMI and Holbaek DMI, where the latter is about $20 \mathrm{~km}$ away from the ESKB site. The approach of using an NWP model was taken due to the straightforward application of the method, and the expected evenness in quality throughout the model area. Because of the small net bias between the HWMs and the reference measurement presented in the results, the bias between the HWMs and the reference measurement is not considered a significant source of error.

For the cases of HVDS and GNB, we found that HWMs are likely to contribute positively to the information of the state of the surface wind field. For HVDS, the difference between $u_{\mathrm{dmi}}^{10 \mathrm{~m}}$ and $u_{\mathrm{ref}}^{10 \mathrm{~m}}$ are seen in Fig. 5 . Here the HWMs are found to be more representative for the coast than the DMI measurement, even for $u_{\mathrm{hwm}}^{s}$. This is seen directly in Table 3, where $u_{\text {hwm }}^{s}$ have both a lower RMSE and bias than the DMI measurement. These differences likely come from the fact that the measurements done at the beach are taken in the internal boundary layer of the sea (maritime IBL), while the DMI observation is measuring in a growing IBL of the land and the city. The change in the surface roughness from the sea to that of the city affects the vertical wind profile. The effective change in surface roughness gives a discontinuity in vertical wind profiles between the beach and the city, so one cannot expect the two profiles to be similar. Because the DMI observation is taken in the IBL of the city, the observation is representative for the city, but not for the very coast.

Figure 4 shows that there are also differences for the GNB session between the HWMs and DMI. The $u_{\mathrm{dmi}}^{10 \mathrm{~m}}$ is overall measuring wind speeds lower than the reference measurement, $u_{\mathrm{ref}}^{10 \mathrm{~m}}$. The DMI station and the reference measurement are approximately $1 \mathrm{~km}$ apart (see Fig. 1). The DMI SYNOP station is $100 \mathrm{~m}$ away from the coastline, whereas the reference measurement was only $5 \mathrm{~m}$ away from the coastline. For easterly wind, as in this case, $u_{\mathrm{dmi}}^{10 \mathrm{~m}}$ is measuring lower wind speeds in general. We claim, based on the RMSE and bias given in Table 3, that in this situation the HWMs (both at $2 \mathrm{~m}$ and extrapolated to $10 \mathrm{~m}$ ) are more representative of the general wind conditions in the area than $u_{\mathrm{dmi}}^{10 \mathrm{~m}}$.

Because of the noncomplex terrain of HVDS and GNB and the onshore winds, it is assumed that the correct surface roughness is that of the sea. However, note that the roughness of the sea depends on the state of the sea, such as the significant wave height (Jones and Toba 2001). This has not been dealt with here because of the relative low wind speeds. The $z_{0}^{\text {hwm }}$ is a little too high for HVDS, but in this case, real user data were included, which will introduce a source of unknown errors. However, it is noted that HVDS is one of the best locations for including real user data when westerly winds are present, as measurements are likely to be done in the maritime boundary layer. The effect of the upstream city is clearly seen from the $u_{\mathrm{dmi}}^{10 \mathrm{~m}}$ measurement in the case of HVDS. DMI ought to reconsider whether the HVDS station should remain a coastal station. It also shows that surfers are better off using their own measurements.

For all of the investigated sites, $u_{\mathrm{clc}}^{10 \mathrm{~m}}$ is performing worst in terms of RMSE. This is most noticeable in Fig. 4, where $u_{\mathrm{clc}}^{10 \mathrm{~m}}$ is overshooting the reference measurement by $2-4 \mathrm{~m} \mathrm{~s}^{-1}$ in general. The values of $z_{0}$ for GNB (Table 3 ) explain this though. The $z_{0}^{\text {nwp }}$ is using a roughness for water that is almost correct in this case, whereas $z_{0}^{\text {clc }}$ is using a typical value of farmland $\left(z_{0}^{\mathrm{clc}}=0.2 \mathrm{~m}\right.$ ) (Arya 2001, their Fig. 10.5). The resolution of the dataset of $z_{0}^{\text {clc }}$ is much higher than $z_{0}^{\text {nwp }}$. This also makes the dataset more vulnerable in areas with discontinuities in surface roughness if the upstream surface roughness is not accounted for. At GNB, the measurements were performed at the beach, so close to the coastline that the measurements will not be far from representing the IBL of the sea. This can be accounted for by taking the wind direction into account and hence using the upwind surface roughness. This must also take the upwind wind fetch into account (Wiernga 1993). An upwind value from $z_{0}^{\text {clc }}$ gives $10^{-4} \mathrm{~m}$, comparable to that of $z_{0}^{\text {nwp }}$.

It is emphasized that the logarithmic wind profile is not valid down to $z=0 \mathrm{~m}$, but only in an inertial sublayer where $z / z_{0} \rightarrow \infty$ and $z f / u_{*} \rightarrow 0$ (where $f$ is the Coriolis parameter) (Tennekes 1973). Wiernga (1993) argues that the lower limit of validity is from $z \approx 20 z_{0}$ to $50 z_{0}$ and that the upper bound is $z \approx 0.1 h-0.2 h$, where $h$ is the boundary layer height. For ESKB using a value of $z_{0}^{\mathrm{clc}}=0.1 \mathrm{~m}$, the lower limit is $z \approx 2-5 \mathrm{~m}$. Using the lowest value of $z_{0}^{\mathrm{nwp}}$ for ESKB, $z_{0}^{\mathrm{nwp}}=5.0 \times 10^{-2} \mathrm{~m}$, one obtains the lower limit as $z \approx 1.0-2.5 \mathrm{~m}$. From these limits it is clear that estimating the roughness length from HWMs faces two main challenges. First, the measurement height will most often be in the interval $2.0-2.2 \mathrm{~m}$, which clearly indicates that using HWMs for quantifying the current wind conditions and for estimating roughness length should only be done with utmost caution for areas for which $z_{0}>0.1 \mathrm{~m}$. Therefore, a background field is needed to determine if an HWM can be trusted or not. Such a background field could potentially come from a land surface model. Also, the extrapolation assumes that both the HWMs and the reference height $(10 \mathrm{~m})$ are in the same IBL [see Eq. (6)]. This limits the validity of HWMs in general to smooth, open areas. The typical users of the handheld anemometer used in this study are sailors, kitesurfers, and farmers, so most measurements will meet this requirement. Second, the duration of an 
HWM will rarely be $10 \mathrm{~min}$ as required by WMO (2008). Standing with an arm raised for 10 min with a handheld anemometer is not realistic. However, users can be encouraged to take several measurements within $10 \mathrm{~min}$ as was done in this study.

Considering the required wind fetch given by Wiernga [1993, their Eq. (6)] for ESKB, the fetch for $z=10 \mathrm{~m}$ is 1.2 and $1.9 \mathrm{~km}$ using the lowest and highest value of $z_{0}$ for ESKB, respectively. For $z=2 \mathrm{~m}$ the corresponding values are 0.2 and $0.3 \mathrm{~km}$. It is, however, only to the west we find an area that can be considered to be a significant change in effective roughness length within this range (based on the CLC dataset; Silva et al. 2007).

Roughness length $z_{0}$ can also be determined by linear regression of $u$ on $\ln z$. The order matters as the errors of $\ln z$ are usually much lower than those of $u$ (Bergeron and Abrahams 1992). This approach was not used in this work though. We expect such roughness lengths to be unreliable in this study for several reasons. First, only two levels are considered here. While assuming a neutral stratification is enough to perform a linear regression, even small errors in wind measurements can result in substantial errors in $u_{*}$ of about $\pm 15 \%$ when only using two levels (Langleben 1974), and the errors in $z_{0}$ is a factor of $k u / u_{*}$ larger (Wiernga 1993). Furthermore, it has no clear, practical implications, and so has little value for the objective of this study.

The ratio $u(z) / \sigma_{u}$ must be constant for the roughness length to be constant, as shown with Eq. (1). The ratio in the case of ESKB5 is plotted in Fig. 6, together with the wind speed and wind direction. The spread of the ratio from the individual HWMs are quite large, as one would suspect due to shorter averaging time. However, when convoluted with a Gaussian kernel the spread of both the reference measurements and the HWMs becomes much smaller. It cannot be argued that the ratios are constant, but based on Fig. 6 one can easily imagine how more HWMs can contribute to finding the true roughness length. A change in wind direction is also seen in Fig. 6 that unavoidably will add some noise to the measured ratio except if the new upstream surface area is uniform within the wind directions experienced. Table 3 gives the average of the ratio and the standard deviation of the ratio $u(z) / \sigma_{u}$ for each case. Not surprisingly, the standard deviation for $u_{\mathrm{hwm}}^{s}$ is higher than that for $u_{\mathrm{ref}}^{10 \mathrm{~m}}$. The absolute values of $u(z) / \sigma_{u}$ for both $u_{\mathrm{hwm}}^{s}$ and $u_{\mathrm{ref}}^{10 \mathrm{~m}}$ in the ESKB cases are comparable.

The RMSE and bias for each case and location are shown in Fig. 7. Is it expected that for ESKB, the bias for the DMI SYNOP station is in some cases high in absolute terms because the DMI station is about $20 \mathrm{~km}$ away. The bias of HWMs is generally lower, indicating that for this area HWMs can be considered to be more representative than the better equipped, but more distant DMI station, which is also seen from the RMSE. For
ESKB3 and ESKB6, both the bias and RMSE for the DMI SYNOP station are large-for example, more than $4 \mathrm{~m} \mathrm{~s}^{-1}$. The weather conditions, including wind direction, are similar to the case of ESKB4 (see Table 2), but for ESKB4 the bias is only $0.01 \mathrm{~m} \mathrm{~s}^{-1}$ and RMSE is $0.79 \mathrm{~m} \mathrm{~s}^{-1}$ (see Table 3). A conclusive reason for this has not yet been found. It is worth noticing that an HWM can be more representative than a traditional SYNOP observation when it is made in an open area. From the results shown in section 4 we recommend not to use the Silva et al. (2007) dataset for roughness lengths, because both $u_{\mathrm{clc}}^{10 \mathrm{~m}}$ WSC and NSC gives higher RMSE and bias than even $u_{\mathrm{hwm}}^{s}$.

The $z_{0}^{\text {nwp }}$ cannot necessarily be expected to be representative of the location where a measurement takes place as it is upscaled to the resolution of the model (see section 2), neither is wind direction taken into account when determining $z_{0}^{\text {nwp }}$. This might explain why $u_{\mathrm{nwp}}^{10 \mathrm{~m}}$, in general, performs worse than $u_{\mathrm{hwm}}^{10 \mathrm{~m}}$ for the ESKB location. This is the case with both NSC and WSC. Therefore, handheld devices that cannot measure the wind direction should not be used for this purpose, or they should be only used for homogeneous terrain, where the wind direction can be estimated from numerical models or traditional measurements.

More important, HWMs can be of a good enough quality to be incorporated into an overview of the state of the atmosphere. This does not necessarily mean assimilating such observations into NWP models, but they can provide complementary aid for the operational meteorologists. This is especially true if the HWMs are extrapolated using a source of $z_{0}$ of good quality, as both RMSE and bias decreases. This can only be considered as valid for smooth $\left(z_{0}<0.1 \mathrm{~m}\right)$ surfaces. Correction for stability was not found to be the highest concern for the cases considered here; thus, there will in practical applications be little or no need for NWP model output making the application simpler to implement.

Using surface fluxes obtained with the Holtslag and Van Ulden (1983) scheme was shown to give better results in the cases presented in this work (see Table 4). The Holtslag and Van Ulden scheme acts as a comparison with the stability correction using the NWP approach. We do see the same order of magnitude in errors using NSC, WSC, or the Holtslag and Van Ulden (1983) scheme when extrapolating the HWMs to $10 \mathrm{~m}$; the overall conclusions will be unchanged related to estimation of roughness lengths. However, because the Holtslag and Van Ulden scheme gives better results than the WRF Model configuration adopted here, we encourage one to favor SYNOP stations if available. While this is encouraging it is noted that the Holtslag and Van Ulden (1983) scheme can in other cases fall 
short with lack of nearby SYNOP stations or with properties of the terrain that were not accounted for in the original scheme. We believe that the Holtslag and Van Ulden scheme gives better results here because of a better consistency between $z_{0}^{\text {ti }}$ and $L$ from Holtslag and Van Ulden, because both are based on measurements on- or near site.

Filtering of poor observations from real user data will probably be the most challenging task in the future.

\section{Conclusions}

Handheld wind measurements obtained with smartphones in open areas can in some cases better resolve the actual wind conditions than wind measurements from even relatively nearby official weather stations. Utilizing HWMs has the potential to aid operational meteorologists in obtaining a near-real-time overview of the state of the atmosphere and bias correcting of NWP surface winds. We find smaller errors in wind speeds obtained from HWMs, even before applying an extrapolation with height, than those from official weather stations about a kilometer away. One advantage of HWMs is that they are not limited by the need for continuous electricity supply and ongoing maintenance. Extrapolating the HWMs using roughness lengths of different origin to the standard height of $10 \mathrm{~m}$ for wind measurements generally yields smaller errors than the raw HWM, both regarding RMSE and bias. Estimating roughness lengths from the high-frequency signal from a handheld anemometer was used to extrapolate HWMs from about $2 \mathrm{~m}$ to a height of $10 \mathrm{~m}$, and these generally give better results than using roughness lengths from an NWP model or a lookup table, respectively. Stability corrections yielded the best results using an empirical scheme based on SYNOP observations, rather than using stability parameters from an NWP model, but overall stability corrections were not found to be of great importance. Furthermore, it is concluded that HWMs should not be used to extract information from areas with roughness lengths above $0.1 \mathrm{~m}$, and thus a background field is required. Utilizing HWMs does indeed have a future potential to be applied at meteorological centers, although it will most likely not happen in the near future, because work with validation of real user data is required before that can be applied.

Acknowledgments. We thank Innovation Fund Denmark for funding of this study. Thanks also are given to agriculturalist Poul Graae for unlimited access to his farmland and to Dr. Juan Munoz-Gomez for valuable technical advice. We also thank the three anonymous reviewers for valuable feedback that has improved the paper significantly.

\section{REFERENCES}

Agüera-Pérez, A., J. C. Palomares-Salas, J. J. G. de la Rosa, and J. M. Sierra-Fernández, 2014: Regional wind monitoring system based on multiple sensor networks: A crowdsourcing preliminary test. J. Wind Eng. Ind. Aerodyn., 127, 51-58, https://doi.org/10.1016/j.jweia.2014.02.006.

Arya, S. P., 1995: Atmospheric boundary layer and its parameterization. World Climate in Cities, Springer, 41-66, https:// doi.org/10.1007/978-94-017-3686-2_3.

_ - 2001: Introduction to Micrometeorology. 2nd ed. Academic Press, 420 pp.

Bergeron, N. E., and A. D. Abrahams, 1992: Estimating shear velocity and roughness length from velocity profiles. Water Resour. Res., 28, 2155-2158, https://doi.org/10.1029/92WR00897.

Businger, J. A., J. C. Wyngaard, Y. Izumi, and E. F. Bradley, 1971: Flux-profile relationships in the atmospheric surface layer. J. Atmos. Sci., 28, 181-189, https://doi.org/10.1175/ 1520-0469(1971)028<0181:fprita $>2.0 . c 0 ; 2$.

Buttner, G., and B. Kosztra, 2001: Manual of CORINE land cover changes. European Environment Agency Rep., 153 pp., https:// land.copernicus.eu/user-corner/technical-library/manual_of_ changes_final_draft.pdf.

Cappelen, J., 2012: Vindstatistik for danske kyststationer 20012010-Hyppighed af stiv kuling og derover (Wind statistics for Danish coastal stations 2001-2010-Frequency of stiff breeze and beyond). Danish Meteorological Institute Tech. Rep., 13 pp.

Clark, M. R., J. D. C. Webb, and P. J. Kirk, 2018: Fine-scale analysis of a severe hailstorm using crowd-sourced and conventional observations. Meteor. Appl., 25, 472-492, https://doi.org/10.1002/ met.1715.

Counihan, J., 1975: Adiabatic atmospheric boundary layers: A review and analysis of the data from the period 1880-1972. Atmos. Environ., 9, 871-905, https://doi.org/10.1016/00046981(75)90088-8.

Ek, M. B., K. E. Mitchell, Y. Lin, E. Rogers, P. Grunmann, V. Koren, G. Gayno, and J. D. Tarpley, 2003: Implementation of Noah land surface model advances in the National Centers for Environmental Prediction operational mesoscale Eta Model. $J$. Geophys. Res., 108, 8851, https://doi.org/10.1029/2002JD003296.

Estellés-Arolas, E., and F. Guevara, 2012: Towards an integrated crowdsourcing definition. J. Inf. Sci., 38, 189-200, https:// doi.org/10.1177/0165551512437638.

Evans, D., 2011: How the next evolution of the internet is changing everything. Cisco Rep., 11 pp.

Gill Instruments, 2017: WindObserver 65. Accessed 15 August 2019, http://gillinstruments.com/products/anemometer/ windobserver-65.html.

Hintz, K. S., H. Vedel, and E. Kaas, 2019a: Collecting and processing of barometric data from smartphones for potential use in numerical weather prediction data assimilation. Meteor. Appl., 26, 733-746, https://doi.org/10.1002/met.1805.

, and Coauthors, 2019b: Collecting and utilising crowdsourced data for numerical weather prediction: Propositions from the meeting held in Copenhagen, 4-5 December 2018. Atmos. Sci. Lett., 921, e921, https://doi.org/10.1002/ASL.921.

Holtslag, A. A. M., and A. P. Van Ulden, 1983: A simple scheme for daytime estimates of the surface fluxes from routine weather data. J. Climate Appl. Meteor., 22, 517-529, https://doi.org/ 10.1175/1520-0450(1983)022<0517:ASSFDE > 2.0.CO;2.

Howe, J., 2006: Crowdsourcing: A definition. Accessed 15 August 2019, http://crowdsourcing.typepad.com/cs/2006/06/crowdsourcing a.html. 
Jiménez, P. A., J. Dudhia, J. F. González-Rouco, J. Navarro, J. P. Montávez, and E. Garcisía-Bustamante, 2012: A revised scheme for the WRF surface layer formulation. Mon. Wea. Rev., 140, 898-918, https://doi.org/10.1175/MWR-D-11-00056.1.

Jones, I. S. F., and Y. Toba, Eds., 2001: Wind Stress over the Ocean. Cambridge University Press, 307 pp., https://doi.org/10.1017/ CBO9780511552076.

Kim, N.-Y., Y.-H. Kim, Y. Yoon, H.-H. Im, R. K. Y. Choi, and Y. H. Lee, 2015: Correcting air-pressure data collected by MEMS sensors in smartphones. J. Sensors, 2015, 245498, https://doi.org/10.1155/2015/245498.

Kouznetsov, R. D., and S. S. Zilitinkevich, 2010: On the velocity gradient in stably stratified sheared flows. Part 2: Observations and models. Bound.-Layer Meteor., 135, 513-517, https:// doi.org/10.1007/s10546-010-9487-y.

Krennert, T., G. Pistotnik, R. Kaltenberger, and C. Csekits, 2018: Crowdsourcing of weather observations at national meteorological and hydrological services in Europe. Adv. Sci. Res., 15, 71-76, https://doi.org/10.5194/asr-15-71-2018.

Langleben, M. P., 1974: On wind profiles over sea ice. Geophys. Res. Lett., 1, 82-85, https://doi.org/10.1029/GL001i002p00082.

Lynch, P., and X. Huang, 1993: Diabatic initialization using recursive filters. Tellus, 46A, 583-597, https://doi.org/10.3402/ tellusa.v46i5.15646.

Mass, C. F., and L. E. Madaus, 2014: Surface pressure observations from smartphones: A potential revolution for high-resolution weather prediction? Bull. Amer. Meteor. Soc., 95, 1343-1349, https://doi.org/10.1175/BAMS-D-13-00188.1.

McNicholas, C., and C. F. Mass, 2018: Smartphone pressure collection and bias correction using machine learning. J. Atmos. Oceanic Technol., 35, 523-540, https://doi.org/10.1175/JTECHD-17-0096.1.

Mellor, G. L., and T. Yamada, 1982: Development of a turbulence closure model for geophysical fluid problems. Rev. Geophys., 20, 851-875, https://doi.org/10.1029/RG020i004p00851.

Met Office, 2017: Met Office Weather Observations Website. Accessed 15 August 2019, https://wow.metoffice.gov.uk/.

Monin, A. S., and A. M. Obukhov, 1954: Dimensionless characteristics of turbulence in the surface layer. Dokl. Akad. Nauk USSR, 93, 223-226.
NCEP, 2000: NCEP FNL operational model global tropospheric analyses. NCAR Computational and Information Systems Laboratory Research Data Archive, accessed 15 August 2019, https://doi.org/10.5065/D6M043C6.

Netatmo SAS, 2017: Netatmo Weathermap. Accessed 15 August 2019, https://weathermap.netatmo.com/.

_ 2018: Netatmo blog. Accessed 15 August 2019, https:// www.netatmo.com/blog/en/weather/understanding.

NSSL, 2016: mPING: Crowdsourcing weather reports. NOAA, accessed 15 August 2019, http://mping.nssl.noaa.gov.

Panofsky, H. A., 1963: Determination of stress from wind and temperature measurements. Quart. J. Roy. Meteor. Soc., 89, 85-94, https://doi.org/10.1002/qj.49708937906.

Paulson, C. A., 1970: The mathematical representation of wind speed and temperature profiles in the unstable atmospheric surface layer. J. Appl. Meteor., 9, 857-861, https://doi.org/ 10.1175/1520-0450(1970)009<0857:TMROWS >2.0.CO;2.

Robustelli, U., V. Baiocchi, and G. Pugliano, 2019: Assessment of dual frequency GNSS observations from a Xiaomi MI 8 android smartphone and positioning performance analysis. Electronics, 8, 91, https://doi.org/10.3390/ELECTRONICS8010091.

Silva, J., C. Ribeiro, and R. Guedes, 2007: Roughness length classification of CORINE land cover classes. European Wind Energy Conf., Milan, Italy, European Wind Energy Association.

Skamarock, W. C., and Coauthors, 2008: A description of the Advanced Research WRF version 3. NCAR Tech. Note NCAR/TN-475+STR, 113 pp., https://doi.org/10.5065/D68S4MVH.

Tennekes, H. H., 1973: The logarithmic wind profile. J. Atmos. Sci., 30, 234-238, https://doi.org/10.1175/1520-0469(1973)030<0234: TLWP $>2.0 . C O ; 2$.

Vaavud, 2019: Vaavud Sleipnir anemometer. Accessed 25 November 2019, http://vaavud.com/support/faq/app-and-wind-meter.

Weatherflow, 2020: Weatherflow anemometers. Accessed 16 March 2020, https://weatherflow.com/wind-weather-meters/.

Wiernga, J., 1993: Representative roughness parameters for homogeneous terrain. Bound.-Layer Meteor., 63, 323-363, https://doi.org/10.1007/BF00705357.

WMO, 2008: Guide to meteorological instruments and methods of observation. WMO Rep. 8 (7th ed.), 716 pp., http://library.wmo.int/ pmb_ged/wmo_8_en-2012.pdf. 